\title{
Self-Driven Pretreatment and Room-Temperature Storage of Water Samples for Virus Detection Using Enhanced Porous Superabsorbent Polymer (PSAP) Beads
}

\section{Wensi Chen}

Georgia Institute of Technology https://orcid.org/0000-0002-6094-2935

\section{Ting Wang}

Georgia Institute of Technology https://orcid.org/0000-0002-4658-7789

\section{Zeou Dou}

Georgia Institute of Technology https://orcid.org/0000-0003-4216-994X

Xing Xie ( $\nabla$ xing.xie@ce.gatech.edu )

Georgia Institute of Technology https://orcid.org/0000-0002-2253-0964

\section{Research Article}

Keywords: Porous polymer, separation, encapsulation, stabilization, virus surveillance.

Posted Date: June 29th, 2021

DOl: https://doi.org/10.21203/rs.3.rs-661557/v1

License: (c) (i) This work is licensed under a Creative Commons Attribution 4.0 International License.

Read Full License 


\section{Abstract}

The continuous emergence of infectious viral diseases has become a major threat to public health. To quantify viruses, proper handling of water samples is required to ensure the accuracy and reliability of the testing results. In this study, we develop enhanced porous superabsorbent polymer (PSAP) beads to pretreat and store water samples for virus detection. By applying PSAP beads to collect water samples, the viruses are captured and encapsulated inside the beads while undesired components are excluded. We have successfully demonstrated that the shelf life of the model virus can be effectively extended at room temperature $\left(22^{\circ} \mathrm{C}\right)$ and elevated temperature $\left(35^{\circ} \mathrm{C}\right)$. Both the infectivity level and genome abundance of the viruses are protected even in a complex medium like untreated wastewater. Under the tested conditions, the viral degradation rate constant can be reduced to more than 10 times using the PSAP beads. Therefore, the enhanced PSAP beads provide a low-cost and efficient sample pretreatment and storage method that is feasible and practicable for large-scale surveillance of viral pathogens in water samples.

\section{Synopsis}

The porous superabsorbent polymer beads can extract and stabilize viruses in water samples for longterm storage at room temperature, thus bypassing the reliance on cold chain and enabling low-cost virus surveillance.

\section{Introduction}

The ongoing pandemic of COVID-19 has been a public health emergency of international concern. ${ }^{1}$ Wastewater surveillance testing is an emerging epidemiological tool to monitor municipal sewage for traces of infectious pathogens in entire communities. ${ }^{2}$ Previous studies on human enteric viruses such as norovirus, hepatitis A virus, and poliovirus have demonstrated that wastewater testing enables early, costeffective, and unbiased community-level surveillance. ${ }^{3-6}$ Recently, wastewater surveillance testing as a powerful platform has been evaluated and applied to supplement clinical measures, monitor the progression of the current pandemic, and provide advance notice of infection dynamics. ${ }^{7-9}$ As of March 2021, more than hundreds of researchers around the world have continually developed and refined sample collection and data analysis methods to monitor wastewater for SARS-CoV-2 RNA, with the goal of providing a near-real-time integrated and quantitative indicator of prevalence, increase, and geographic reach of COVID-19 within a population. ${ }^{10-15}$

To detect and quantify viral species in water samples, proper pretreatment and continuous cold storage of water samples are required to ensure the measurements are accurate and reliable in the subsequent lab tests. ${ }^{16-18}$ Temperature is generally acknowledged to be the most critical factor determining viral survival in the environment. ${ }^{19-21}$ In wastewater, as temperature increases, bacterial and protozoan metabolic processes accelerate, predation increases, and enzymes produced by 
microorganisms can degrade viral capsids and damage the integrity of viral genomes. ${ }^{22,}{ }^{23}$ Selfdegradation of the viral genomes also occurs through hydrolytic cleavage of the phosphodiester bond. ${ }^{24}$, ${ }^{25}$ In addition, both the sugar and base moieties of nucleic acids are susceptible to oxidation by reactive oxygen species. ${ }^{26,27}$ Although the reaction mechanisms are different, the kinetics of the as-mentioned enzymatic and non-enzymatic degradation processes all highly depends on the temperature, in which a higher temperature generally results in a faster reaction rate.

However, refrigeration storage and transportation may not be feasible or sufficient, especially in resourcelimited settings. The large-scale surveillance testing may need extraordinarily high cost to implement the sample storage system. In some cases, the low and variable occurrence of viral pathogens requires a large volume of water samples to concentrate the target viruses for quantification, which brings extra burdens on the sample storage and transportation. ${ }^{28,29}$ On the other hand, since the virus quantification techniques such as PCR method may not be available on-site, processing the water samples within 1 or 2 days may not be practical due to the delay of shipping samples to a centralized laboratory. Even with temperature regulation, the extended holding time may still increase viral inactivation and genome degradation, which causes high uncertainty in the testing results as well as the health risk assessment. ${ }^{30-}$ 32

To bypass the reliance on the cold chain from storage to shipping, researchers have developed several room-temperature storage methods for biomolecules such as DNA and RNA. ${ }^{33}$ For example, GenPlates are commercially available products for storing and transporting biofluid samples at room temperature, in which the nucleic acid molecules are entwined in the fibrous pores of the cellulose filter and then air-dried for effective protection. ${ }^{34}$ RNA storage is more challenging compared with DNA due to its relatively unstable single-stranded structure. Fabre and co-workers developed a technology that dried RNA samples in the presence of a stabilizer in stainless steel minicapsules. ${ }^{35}$ The air- and water-tight capsules isolated RNA from the atmosphere and maintained it in an anhydrous and anoxic environment to enable reliable long-term storage at room temperature. However, these techniques still cannot substitute the conventional method for large-scale water sample preservation and are limited by (i) long sample treatment time, (ii) inadequate treatment volume, (iii) high cost, (iv) complex operation, and/or (v) uncertain protective capacity in wastewater matrix.

Superabsorbent polymers (SAPs) can absorb and retain extremely large amounts of a liquid (e.g., water) relative to their own weight. ${ }^{36}$ Due to their superior absorbency and unique network structure, they have been investigated and applied for the purification and concentration of valuable biomaterials in biomedical and pharmaceutical fields since the 1980s. ${ }^{37-42}$ Researchers have also applied SAP beads to concentrate microalgae cells for hydrogen production or biofuel extraction. ${ }^{43,44}$ In our previous study, we have successfully developed and demonstrated porous superabsorbent polymer (PSAP) beads for fast, effective, and self-driven "microfiltration" treatment of biofluid samples. ${ }^{45}$ The PSAP beads allowed the sorption of analytical targets that are typically small molecules or macromolecules (e.g., ions, sugars, proteins, and nucleic acids) while rejecting large undesired components (e.g., bacteria and blood cells). 
Therefore, the potential analytical targets could be effectively preserved even without refrigeration, because microbial spoilage and hemolysis effects were avoided, and the PSAP beads provided an intrinsic buffer system to stabilize the target species. For example, when preserved by the PSAP beads, the plasma sample with dosed catalase, a common enzyme in the human body, remained higher than $90 \%$ of catalase activity even after 7 days at room temperature, while the control group lost $80 \%$ of catalase activity.

In this study, we fabricate enhanced PSAP beads for self-driven pretreatment and roomtemperature storage of water samples for virus detection. The design of the PSAP beads combines a well-controlled porous structure, excellent water absorption properties, and uniform dispersion of the stabilizer on the inner surface of the beads. Therefore, viruses in water samples can be spontaneously captured by the beads with water uptake and immediately preserved. Simultaneously, some impurities and interferences are excluded and discarded to avoid their impact on the testing targets. We hypothesize that the unique features of the PSAP beads would realize adequate stabilization capability for viruses to realize shelf-life extension at room temperature or even elevated temperatures. Thus, refrigeration during the water sample storage and transportation may not be necessary. To demonstrate this hypothesis, we have measured the efficiency of PSAP beads for viral recovery, and tested both infectivity level and nucleic acid abundance of the model virus captured by the beads during short-term and long-term storage to simulate field conditions. The enhanced PSAP beads show excellent promise as an alternative nonrefrigeration preservation technique for viruses in water samples.

\section{Experimental Methods}

\subsection{Fabrication and Characterization of PSAP Beads}

The design principle and synthesis of the pristine PSAP beads were previously described. ${ }^{45}$ In brief, the reaction mixture containing $6 \mathrm{wt} \%$ sodium acrylate, $4 \mathrm{wt} \%$ acrylamide, $10 \mathrm{wt} \%$ poly(ethylene glycol) (PEG, average $\mathrm{M}_{\mathrm{n}}=6000 \mathrm{~g} \mathrm{~mol}^{-1}$ ) and $0.2 \mathrm{wt} \% \mathrm{~N}^{\prime} \mathrm{N}^{\prime}$-methylenebisacrylamide in DI water was prepared. The liquid mixture was fully dispersed and degassed by nitrogen bubbling for $5 \mathrm{~min}$. The initiator, ammonia persulfate, was added to the aqueous solution to reach a concentration of $0.3 \mathrm{wt} \%$. The precursor was then transferred into a 96 -well plate $\left(15 \mu \mathrm{L}\right.$ per well) and heated at $70^{\circ} \mathrm{C}$ for $15 \mathrm{~min}$. The resultant polymer beads were thoroughly washed by ethanol to remove the PEG and fully dehydrated (Figure S1). To prepare enhanced PSAP beads, the monomers, crosslinker, and porogen were added to a well-dispersed bovine serum albumin (BSA) solution (0.05-0.3 wt\%). The subsequent procedures are the same as the synthesis of the pristine beads. The morphology of dried PSAP beads was characterized by scanning electron microscopy (SEM, Hitachi SU8230, Tokyo, Japan) at $3 \mathrm{kV}$. All specimens were coated with gold for $10 \mathrm{~s}$ at $20 \mathrm{~mA}$ using a sputter coater (Quorum Q150T ES, Lewes, United Kingdom). The swelling properties of the PSAP beads in DI water and saline solutions were tested, in which weights of 
both the dried and hydrated beads were measured to calculate the water absorbency: $S=\left(m_{\text {hydrated }}{ }^{-}\right.$ $\left.m_{\text {dried }}\right) / m_{\text {dried. }}$

\subsection{Viral Target Recovery Test}

The virus absorption and recovery performance of the PSAP beads were determined using bacteriophage MS2 (ATCC 15597-B1) as the model virus. Bacteriophage MS2 was cultured with the host bacterium, Escherichia coli (E. coli, ATCC 15597), in tryptic soy broth at $35^{\circ} \mathrm{C}$ overnight. The suspension was subsequently centrifuged at $4000 \mathrm{rpm}$ for $5 \mathrm{~min}$, and the supernatant was filtered through a $0.2 \mu \mathrm{m}$ syringe filter to remove all $E$. coli cells. The purified MS2 was then diluted and dispersed in saline media to achieve a concentration of $\sim 10^{6} \mathrm{PFU} \mathrm{mL}{ }^{-1}$. The concentration of MS2 was quantified by the double agar layer method with three replicates for each sample. ${ }^{45}$ The recovery efficiency of the viruses was determined by comparing the concentration of the viruses released from the PSAP beads $\left(c_{t}\right)$ and in the original liquid sample $\left(c_{0}\right)$. In brief, 5 PSAP beads were applied to treat $2 \mathrm{~mL}$ of the virus sample. The beads were taken out until reaching swelling equilibrium and then weighted $(m)$. Next, the hydrated beads in a clean tube were immersed by $2 \mathrm{~mL}$ of added water and then broken by $5 \mathrm{~s}$ ultrasonication using a probe sonicator (Qsonica Q125, Newtown, CT). Thus, the dilution factor $(D F)$ for the target species was calculated: $D F=\left(m+m_{\text {water }}\right) / m$. Next, the viral concentration of the well-mixed suspension $\left(c_{t}\right)$ was measured to analyze the recovery efficiency: Recovery $(\%)=\left(c_{t} / c_{0}\right) \times D F \times 100$.

\subsection{Viability of Virus under Different Storage Conditions}

The viability of the model virus, bacteriophage MS2, during the 1-week storage was measured under different storage conditions. The purified MS2 was dispersed in a saline medium containing $0.1 \%$ $\mathrm{NaCl}$ to achieve an initial concentration of $\sim 10^{6} \mathrm{PFU} \mathrm{mL}{ }^{-1}$. After preparing the liquid sample, PSAP beads were applied to treat the virus suspension for $15 \mathrm{~min}$, which were then separated from the liquid and divided into two glass vials wrapped with aluminum foil. Next, the two vials were stored at room temperature $\left(22^{\circ} \mathrm{C}\right)$ and elevated temperature $\left(35^{\circ} \mathrm{C}\right)$, respectively. Meanwhile, another three vials containing virus suspensions as the control groups were wrapped with aluminum foil and stored at $4^{\circ} \mathrm{C}$, $22^{\circ} \mathrm{C}$, and $35^{\circ} \mathrm{C}$, respectively. The concentrations of infectious MS2 inside the hydrated PSAP beads and in the liquid controls were monitored along the storing time. All viral infectivity data collected were normalized to the initial values for analysis. In addition, first-order inactivation rate constants were determined by linear regression of the $\log _{10}$-transformed infectivity data versus time $\left(k, \log _{10} \mathrm{PFU} \mathrm{mL}-1\right.$ day $\left.^{-1}\right)$. All rate constants are expressed with $95 \%$ confidence intervals.

\subsection{Detection of Viral Genome during Long Term Storage}


The storage performance of the PSAP beads for viral RNA in the saline $(0.1 \% \mathrm{NaCl})$ was monitored for 6 weeks. The operation procedures, including the virus suspension preparation, PSAP treatment, and viral target recovery, were similar to the viability tests. To quantify the viral genome concentration, the total RNA of the viral target, either in liquid control or recovered from the PSAP beads, was extracted using QIAmp viral RNA mini kit (Qiagen, Valencia, CA). Then, one-step quantitative reverse transcription PCR (RT-qPCR) assay was performed with StepOnePlus real-time PCR (Applied Biosystems, Foster City, $\mathrm{CA}$ ) using the TaqMan probe kit (details described in Supporting Information). The number of gene copies at different sampling times was normalized to analyze the viral genome decay. The long-term storage performance of the PSAP beads was also demonstrated using raw wastewater collected from a local wastewater treatment plant. The $\mathrm{pH}$, alkalinity, nutrient level, and suspended solids data were provided by the operator at the plant (Table S1). The experimental procedures were similar, excepted a filtration step $(0.2 \mu \mathrm{m}$ filter) was added before the RNA extraction for the liquid control samples to minimize the influence of PCR inhibitors. Meanwhile, the sample containing viruses recovered from the PSAP beads by ultrasonication was directly used for the RNA extraction.

\section{Results And Discussion}

\subsection{Enhanced PSAP Beads}

The PSAP beads are designed to absorb viral pathogens in water samples at the point of collection for easy pretreatment and immediate preservation, thus improving the accuracy and reliability of results generated in the subsequent lab tests. A proposed process of using the PSAP beads at the point of sample collection and subsequently recovering the viruses from the beads at a laboratory is shown in Figure 1a and described as follows: i) the PSAP beads are preloaded in a sterile container with a sieve on top; ii) water sample is collected and infused into the container; iii) the beads swell fast, absorbing water together with viruses while excluding large undesired components (e.g., microorganisms and other particles); iv) the leftover liquid is poured out, leaving only the beads with the captured viruses in the container; v) the sieve is removed, and a lid is put on the container for storage and transportation; vi) the virus-containing beads are aliquoted into several sterile test tubes; and vii) the viruses are released from the beads by ultrasonication and then analyzed.

We have successfully used a dry-bath method to prepare PSAP beads via polymerization-induced phase separation (Figure S1). As shown in Figure 1b, the interconnected pores inside the beads construct water channels. The size of the water channels is mainly determined by the pore structure of the beads. By adjusting the porogen amount in the precursor, this critical parameter can be tuned to control the threshold diameter of absorbable species. ${ }^{45}$ Following the design principles, the PSAP beads have been optimized to enable an effective separation of viruses $(<0.5 \mu \mathrm{m})$ and undesired large components $(>1$ $\mu \mathrm{m}$ ) in water samples by absorbing the former inside and excluding latter outside the beads (optimization process not shown in this study). Thus, the viruses stored inside the beads will not be affected by those undesired components. In addition, the PSAP beads were modified by loading a stabilizer in the polymer scaffold to enhance the interaction between the absorbed viruses and the polymer network for 
immobilization and better preservation. Albumin such as recombinant human albumin has been reported as a stabilizer for variable viral vaccines including live-attenuated viral vaccines and viral vector

vaccines. ${ }^{46,47}$ Therefore, in this work, we chose BSA as a potential stabilizer for modification of the PSAP beads. The stabilizer was added to a reaction mixture containing monomers, crosslinker, initiator, and porogen. Once the polymerization reaction was completed, the sacrificial porogen was removed to reveal the porous structure, but the stabilizer remained in the resultant PSAP beads. The as-obtained dry beads were white-colored, millimeter-sized, and bullet-shaped (Figure 1c). After swelling in the saline solution with $0.1 \% \mathrm{NaCl}$, the beads became hydrated and turned translucent later. It took only $15 \mathrm{~min}$ for the beads to reach swelling equilibrium, during which the bead diameter increased from $\sim 1 \mathrm{~mm}$ to $\sim 5 \mathrm{~mm}$ (Figure $1 d)$.

\subsection{Viral Recovery Performance}

Scanning electron microscopy (SEM) was applied to characterize the morphologies of the PSAP beads. Figure 2a and Figure S2 show the SEM images of the beads prepared by precursors with different amounts of BSA. The characterization results illustrate that all beads have similar pore size and porosity, which means the addition of BSA has negligible effects on the pore structure formation. Meanwhile, as the BSA loading increases, more nanosized BSA particles are uniformly distributed in the PSAP beads to coat the polymer surface. The water absorption capacity of the pristine PSAP beads without BSA modification depends on the porosity, crosslinking degree, charge density, and polymer concentration of the polymer network. ${ }^{48}$ These four factors are related to the concentration of the porogen, the crosslinker, the ionic comonomer, and the total monomers in the initial reaction precursor, respectively. As for the modified PSAP beads, the water absorption capacity decreases due to the existence of BSA (Figure $2 b$ ). This influence is particularly obvious in DI water medium, in which the pristine beads have an equilibrium water absorbency of $\sim 280 \mathrm{~g} \mathrm{~g}^{-1}$, but the modified beads have an equilibrium water absorbency of $\sim 160$ to $145 \mathrm{~g} \mathrm{~g}^{-1}$. The reason is probably that the introduction of BSA reduces the effective charge density of the polymer network, resulting in a lower absorption capacity. In saline media, although the absorption capacity decreases as the BSA loading amount increases, the difference among the PSAP beads is little. The beads have an average water absorbency of $\sim 85 \mathrm{~g} \mathrm{~g}^{-1}$ in $0.1 \% \mathrm{NaCl}$ solution, which gradually decreases as the salinity increases and reaches $\sim 45 \mathrm{~g} \mathrm{~g}^{-1}$ in $0.5 \% \mathrm{NaCl}$ solution.

In order to evaluate the target recovery efficiency using the PSAP beads, bacteriophage MS2 was selected as the model virus. The PSAP beads prepared with different BSA loadings were applied to treat DI water or saline solutions dosed with bacteriophage MS2. Figure 2c presents the recovery efficiency for the viable viruses after the treatment. For the pristine PSAP beads with $0 \% \mathrm{BSA}$, the recovery efficiency is only $~ 50 \%$ in DI water, although the diameter of the bacteriophage MS2 $(\sim 27 \mathrm{~nm})$ is much smaller than the average pore size of the beads $(>100 \mathrm{~nm})$. This is probably because the surfaces of both the bacteriophage MS2 and the PSAP polymer network are negatively charged, which causes difficulty in the sorption of viruses by the PSAP beads, especially in a medium with low ionic strength. However, the increased ionic strength results in a compression of the electric double layer developed around the 
viruses, which significantly reduces the electrostatic repulsion between the viral surface and polymer surface. ${ }^{49,50}$ Thus, the recovery efficiency increases to $~ 85 \%$ in $0.1 \% \mathrm{NaCl}$ solution and almost $100 \%$ in $0.5 \% \mathrm{NaCl}$ solution using the pristine beads. Meanwhile, the PSAP beads with an extra-low BSA amount (e.g., $0.05 \%$ ) can achieve a complete MS2 recovery even in DI water since the loaded BSA can provide binding sites with a stronger affinity to the viruses.

\subsection{Viral Infectivity Protection}

Previous studies have reported that infectious viruses require sufficient genomic integrity for translation and replication, and functional capsid for protection of genome and recognition of host cells. ${ }^{51,52}$ Thus, it is incredibly challenging to avoid rapid decay of viral infectivity without refrigeration. The shelf-life extension ability of the PSAP beads was first evaluated using the saline medium dosed with bacteriophage MS2. After the PSAP treatment, the viral infectivity in the liquid control and the hydrated beads was monitored by the plaque assay for 7 days at three different temperatures $\left(4-35^{\circ} \mathrm{C}\right)$. To generalize infectivity behavior across time, all data collected was normalized to the initial baseline value for each condition. As shown in Figure 3a, the liquid sample stored at $4^{\circ} \mathrm{C}$ maintains $27 \%$ of viral infectivity after the 7-day storage. As expected, the viral inactivation and infectivity reduction significantly accelerate as the temperature increases. The normalized viral infectivity of the liquid sample stored at room temperature $\left(22^{\circ} \mathrm{C}\right)$ remains only $0.22 \%$ after the 7-day storage. When the storage temperature increases to $35^{\circ} \mathrm{C}$, the liquid sample loses more than $99 \%$ of viral infectivity within only 1 day, and almost complete degradation happens after 3 days due to the fast denaturation of viral capsid and subsequent destruction of genomic structure.

The infectivity of the viruses preserved by the PSAP beads is investigated and compared with that in liquid controls. As illustrated in Figure $3 \mathrm{~b}$, when the storage temperature is $22^{\circ} \mathrm{C}$, the pristine beads with $0 \%$ BSA have a similar performance as the liquid control sample, in which $0.18 \%$ of viral infectivity is left after 7 days. This means that the preservation capability of the pristine beads is inadequate to reduce the self-degradation of the viruses under such conditions. In contrast, the viruses stored inside the PSAP beads with $0.05 \%$ BSA can remain higher than $5.8 \%$ of infectivity after the 7-day storage. In addition, the preservation efficacy is critically dependent on the stabilizer loading amount. The higher BSA loading can enhance the immobilization of viruses, protect them against thermal damages, thus significantly improve the preservation performance. Under the same storage conditions, the residual viral infectivity level in the PSAP with $0.1 \%$ BSA is $26 \%$, which achieves comparable performance as the liquid sample stored with refrigeration. When the BSA loading is further increased to $0.2 \%$, the residual viral infectivity level in the PSAP beads reaches $52 \%$ after 7-day storage, which is far beyond the performance of refrigeration storage at $4^{\circ} \mathrm{C}$.

Since temperature is the primary factor for viral inactivation, we evaluated the preservation performance for viruses using the PSAP beads at $35^{\circ} \mathrm{C}$. The results in Figure $3 \mathrm{c}$ show that although the viral inactivation rate significantly increases compared with room temperature storage, the PSAP beads still can provide protection to viral targets at an elevated temperature. Even for the pristine PSAP beads, 
the residual infectivity level remains $6.7 \%$ after 1 day and $0.11 \%$ after 3 days because the limited substance transportation and diffusion in the beads probably slow down the thermal-induced viral inactivation. ${ }^{53}$ Owing to the immobilization effects, the modified PSAP beads can further stabilize the viruses and improve their viability at elevated temperature. The PSAP beads with $0.1 \%$ BSA achieve a 7day survival rate of $0.3 \%$ for bacteriophage MS2. With sufficient stabilizer loading, the 7-day survival rate at $35^{\circ} \mathrm{C}$ can be remarkably improved to $15 \%$ using the beads with $0.2 \%$ BSA. In addition, to investigate the light effects on the viral shelf life, we conducted similar storage experiments at $22^{\circ} \mathrm{C}$ with 12 hours of indoor light illumination every day. The results indicate a clear improvement of viral infectivity using the PSAP bead entrapment over maintaining the sample in the liquid state for the duration of the study because the hydrated PSAP beads may block part of the light, and avoid or reduce photo-induced inactivation reactions (Figure S3, details described in Supporting Information).

Based on the experimental results, we applied a first-order reaction model to simulate infectivity reduction kinetics and directly quantify preservation efficacy. As shown in Figure 3d, the rate constant for the log infectivity reduction is $0.071 \log _{10} \mathrm{PFU} \mathrm{mL} \mathrm{m}^{-1} \mathrm{day}^{-1}$ for the liquid sample stored at $4^{\circ} \mathrm{C}$. At room temperature $\left(22^{\circ} \mathrm{C}\right)$, the reduction rate constants of the liquid samples increase to $0.371 \log _{10} \mathrm{PFU} \mathrm{mL}-1$ day $^{-1}$. At an elevated temperature $\left(35^{\circ} \mathrm{C}\right)$, the rate constant of viral infectivity reduction in the liquid sample reaches $1.645 \log _{10} \mathrm{PFU} \mathrm{mL}{ }^{-1}$ day $^{-1}$. As mentioned, the PSAP beads can effectively improve the preservation of the viruses stored inside the beads. A similar trend is also observed from the results of kinetics analysis. Under the tested conditions, the degradation rate constants can be reduced by up to more than ten times. When the storage temperature is $22^{\circ} \mathrm{C}$, the rate constant of viral infectivity reduction in the PSAP beads varies from 0.369 to $0.035 \log _{10} \mathrm{PFU} \mathrm{mL}^{-1}$ day ${ }^{-1}$ as the BSA loading continues to increase. When the storage temperature is $35^{\circ} \mathrm{C}$, the rate constant in PSAP with $0.2 \%$ BSA can be as low as a thirteenth of that in the liquid sample $\left(0.124 \mathrm{vs}\right.$. $1.645 \mathrm{PFU} \mathrm{mL}^{-1}$ day $\left.^{-1}\right)$. These results demonstrate that PSAP beads can achieve a comparable or even lower rate constant for viral infectivity reduction at room temperature than the refrigeration storage.

\subsection{Viral Genome Stabilization}

Following the successful demonstration of the PSAP beads for viral infectivity protection, we set out to evaluate the capability of this method for viral genome stabilization in the saline medium under long-term ambient conditions. A storage study was performed to examine and compare the genome stability behavior of bacteriophage MS2 stored in liquid form (Figure 4a) or immobilized in the PSAP beads with $0.2 \%$ BSA (Figure 4b). The RT-qPCR assay was applied to estimate the damage to the genomes and quantify the residual RNA level. ${ }^{54}$ Different from the infectivity tests, the RT-qPCR assay measures amplification signals of a specific genome region according to the designed primer set. Thus, even if the destruction of viruses compromises the genomic integrity, the calculated residual RNA level is not affected if the targeted RNA segments still exist. For the frozen liquid sample stored at $-25^{\circ} \mathrm{C}$, the sample is pre-portioned before the freezing and only thawed once for each testing. However, a single freeze-thaw cycle causes higher than $10 \%$ of RNA degradation due to the generation of ice crystals and 
unfavorable interaction between the ice crystals and viruses. ${ }^{19,55}$ As shown in Figure 4 a, the residual RNA level varies from $80 \%$ to $87 \%$ after the 6 -week storage at $-25^{\circ} \mathrm{C}$. When the storage temperature is above freezing point, the freeze-thaw damage can be circumvented, but the accelerated thermal-induced RNA degradation is unavoidable. The liquid sample stored at $4{ }^{\circ} \mathrm{C}$ has a residual RNA level of $93 \%$ after 1 week, which decreases to $81 \%$ after 3 weeks and eventually reaches $75 \%$ after the 6-week storage. Although the viral genome degradation is much slower than the infectivity reduction, the degradation rate still significantly increases at room temperature and elevated temperature. It shows that the residual RNA level remains $49 \%$ for the liquid sample stored at $22^{\circ} \mathrm{C}$ after 1 -week storage, which gradually decreases to $8.4 \%$ after 6 weeks. When the storage temperature is $35^{\circ} \mathrm{C}$, the residual RNA level is even down to $3.2 \%$ after only 1 week and continuously declines to $0.17 \%$ at the end of the storage period.

In contrast to the frozen or liquid samples, the PSAP beads retain intact RNA fragments of the viruses entrapped in the beads despite the temperature change (Figure 4b). The results indicate that the residual RNA level remains higher than $95 \%$ at room temperature after 6 -week storage. At the elevated temperature, viruses stored inside the beads have a residual RNA level as high as $91 \%$ even after 6 -week storage. As mentioned, due to the effective immobilization, the beads with sufficient stabilizer loading can protect viral capsids from denaturation, maintain the structural integrity of the viruses, and preserve the viral infectivity. Thus, the stabilized viral capsid can in turn slow down the destruction of viral genomes. In addition, since the diffusion rate within the beads is restrained by the crosslinked polymer network, the hydrolysis process that causing nucleic acid reduction may be slowed down. Thus, even the exposed and released nucleic acids can still be stabilized in the beads if the viral capsids are completely damaged. The PSAP beads show effective stabilization performance for vulnerable and highly reactive naked RNA segments, which achieve higher than $85 \%$ of residual RNA level at room temperature and above after 1 week (Figure S4).

\subsection{Application in Untreated Wastewater}

To investigate the impacts of water properties on the viral stabilization performance, we assess the applicability of the PSAP beads to preserve real wastewater samples dosed with the model virus. Different from the simple saline medium, untreated wastewater may contain various ions, organic compounds, suspended solids, and live microorganisms, which make it a highly complex system. The results in Figure 5a show the viral RNA reduction in the liquid samples during the 6-week storage at different temperatures. Under the same conditions, the freeze-thaw cycle results in a higher RNA reduction in the raw wastewater than that in the saline medium. The residual RNA level is $70 \%$ for the wastewater sample, and $82 \%$ for the saline sample stored at $-25^{\circ} \mathrm{C}$. It is probably caused by the contaminants in the wastewater that interfere with ice crystal formation and intensify the viral genome damages. On the other hand, counter-intuitively, the apparent residual RNA levels of the wastewater samples stored in liquid form with or without refrigeration are all higher than the corresponding value in the saline medium (Figure 4a). After 6-week storage, the residual RNA level of the wastewater samples is $81 \%$ at $4{ }^{\circ} \mathrm{C}, 17 \%$ at $22^{\circ} \mathrm{C}$, and $1.3 \%$ at $35^{\circ} \mathrm{C}$. The corresponding value of the saline samples is $75 \%, 8.4 \%$, and $0.17 \%$, respectively. A possible reason for this is that the model virus we chose (i.e., bacteriophage MS2) is a common phage, 
and its host bacterial cells (e.g., E. coli) are widely found in untreated wastewater. ${ }^{56}$ The existing host bacteria may shield the viruses against degradation, and possible virus replication under suitable conditions partially offsets the decay of the initially dosed viruses. In addition, the suspended microparticles in water samples have been reported to correlate with a lower decay rate of viral RNA through surface adsorption. ${ }^{19}$

In contrast, since bacteria cells and particles larger than the water channels of the beads are excluded and removed after the PSAP treatment, they cannot affect the virus degradation pathway (Figure S5, details described in Supporting Information). The results in Figure 5b indicate that PSAP beads can achieve similar stabilization performance at room temperature for viruses in untreated wastewater as in saline medium. After 6 -week storage at $22^{\circ} \mathrm{C}$, almost no viral RNA reduction is detected in the beads. When the storage temperature is increased to $35^{\circ} \mathrm{C}$, the viral RNA reduction rate significantly increases even under the protection provided by the beads. Even so, the PSAP beads can still endure such harsh conditions and extend the residual RNA level to $16 \%$ after 6 -week storage at $35^{\circ} \mathrm{C}$. The result also confirms that the actual viral reduction is much faster in wastewater than in saline medium if there are no interference factors (Figure $4 \mathrm{~b}$ ). Although this technique remains to be investigated under varying conditions and using water-borne viral pathogens, the reported results demonstrate the feasibility and robustness of the PSAP beads in preserving viruses in water samples.

\subsection{Stabilization Mechanisms of the PSAP Beads}

As demonstrated, the PSAP beads show excellent performance in viral sample preservation for both infectivity protection and genome stabilization. There may be several possible mechanisms acting synergistically to improve the stability of the viruses stored inside the beads. The well-controlled porous structure of the PSAP beads provides a physical barrier that easily removes undesired impurities such as bacteria and other particles for virus detection. Our previous study has confirmed that PSAP treatment could effectively avoid the impact of bacteria together with their released protease on the protein target encapsulated inside the beads. ${ }^{45}$ It can be deduced that similar effects should apply to virus preservation. The $\mathrm{pH}$ inside the beads was pre-set to a designed value slightly higher than 7 , providing an intrinsic buffer system. In addition, BSA stabilizer was used to modify the PSAP beads and enhance the affinity between the viruses and the polymer network. Thus, once absorbed and entrapped by the beads, the self-degradation of the viruses may be reduced due to the effective immobilization of viruses on the inner surface of the beads. Since BSA contains reactive thiol groups, the loaded BSA itself can work as a sacrificial agent to reduce damages on the viruses under oxidative stress. Meanwhile, the decomposition of viral capsids and genomes caused by enzymatic and non-enzymatic hydrolysis is also probably slowed down as the molecular diffusion is minimized in the polymer network. The hypothesized mechanisms proposed here provide a conceptual framework, more efforts are still required to better understand the involvement of various possible pathways of virus stabilization inside the PSAP beads.

In summary, we used a simple method to encapsulate viruses in the PSAP beads loaded with the BSA stabilizer for long-term ambient storage and subsequent on-demand recovery and laboratory

Page $11 / 22$ 
analysis. The PSAP beads have been demonstrated to effectively mitigate thermal-induced degradation of the model virus and successfully achieve excellent room-temperature preservation performance. In a saline medium, the viral infectivity in the PSAP beads with $0.2 \%$ BSA is as high as $52 \%$ after 1 -week storage at room temperature, and the residual RNA level remains higher than $95 \%$ after 6 -week storage, which are even better than the results of refrigeration storage ( $27 \%$ and $75 \%$, respectively). In raw sewage, the PSAP beads still can achieve a residual RNA level of $\sim 100 \%$ at $22^{\circ} \mathrm{C}$ and $16 \%$ at $35^{\circ} \mathrm{C}$ after 6 -week storage, which is remarkable in such a complex medium and under such challenging conditions. The same stabilization, recovery, and analysis approach demonstrated in this work using the model virus can apply to other viruses, including infectious viral pathogens. Therefore, the novel PSAP beads provide a low-cost, time-efficient, and environmentally friendly technique to possibly eliminate the cold chain and temperature regulations of viral sample storage and transportation. This technique also promotes flexibilities of virus detection in both location and time, enabling the remote collection of water samples from distributed regions and on-demand testing in centralized facilities. Overall, it could be compatible with advanced epidemiology tools for disease control and risk assessment during the current or future pandemics, especially in resource-limited settings and for the medically underserved population.

\section{Declarations}

\section{Author Information}

\section{Corresponding author}

*E-mail: xing.xie@ce.gatech.edu

\section{Author contributions}

W.C. and X.X. conceived and designed the experiments. W.C performed most of the experiments. T.W. helped on fluorescent microscope imaging. Z.D. assisted in the material characterization. The manuscript was written through contributions of all authors. All authors have given approval to the final version of the manuscript.

\section{Notes}

The authors declare no competing financial interest.

\section{Acknowledgement}

We thank Dr. Gayathri Ram Mohan and Dr. Shih-Chi Weng for helpful technical discussions about wastewater sample handling. W.C. and T.W. are grateful for the fellowship provided by the China Scholarship Council.

Competing interests: The authors declare no competing interests. 


\section{References}

1. Dong, E.; Du, H.; Gardner, L., An interactive web-based dashboard to track COVID-19 in real time. The Lancet infectious diseases 2020, 20 (5), 533-534.

2. Asghar, H.; Diop, O. M.; Weldegebriel, G.; Malik, F.; Shetty, S.; El Bassioni, L.; Akande, A. O.; Al Maamoun, E.; Zaidi, S.; Adeniji, A. J., Environmental surveillance for polioviruses in the Global Polio Eradication Initiative. The Journal of infectious diseases 2014, 210 (suppl_1), S294-S303.

3. Yan, T.; O’Brien, P.; Shelton, J.; Whelen, A.; Pagaling, E., Municipal wastewater as a microbial surveillance platform for enteric diseases: a case study for Salmonella and salmonellosis. Environmental science \& technology 2018, 52 (8), 4869-4877.

4. McCall, C.; Wu, H.; Miyani, B.; Xagoraraki, I., Identification of multiple potential viral diseases in a large urban center using wastewater surveillance. Water research 2020, 184, 116160.

5. $\quad$ Farkas, K.; Cooper, D. M.; McDonald, J. E.; Malham, S. K.; de Rougemont, A.; Jones, D. L., Seasonal and spatial dynamics of enteric viruses in wastewater and in riverine and estuarine receiving waters. Science of the Total Environment 2018, 634, 1174-1183.

6. Kroiss, S. J.; Ahmadzai, M.; Ahmed, J.; Alam, M. M.; Chabot-Couture, G.; Famulare, M.; Mahamud, A.; McCarthy, K. A.; Mercer, L. D.; Muhammad, S., Assessing the sensitivity of the polio environmental surveillance system. PloS one 2018, 13 (12), e0208336.

7. Larsen, D. A.; Wigginton, K. R., Tracking COVID-19 with wastewater. Nature Biotechnology 2020, 38 (10), 1151-1153.

8. Peccia, J.; Zulli, A.; Brackney, D. E.; Grubaugh, N. D.; Kaplan, E. H.; Casanovas-Massana, A.; Ko, A. I.; Malik, A. A.; Wang, D.; Wang, M., Measurement of SARS-CoV-2 RNA in wastewater tracks community infection dynamics. Nature Biotechnology 2020, 38 (10), 1164-1167.

9. $\quad$ Graham, K. E.; Loeb, S. K.; Wolfe, M. K.; Catoe, D.; Sinnott-Armstrong, N.; Kim, S.; Yamahara, K. M.; Sassoubre, L. M.; Mendoza Grijalva, L. M.; Roldan-Hernandez, L., SARS-CoV-2 RNA in Wastewater Settled Solids Is Associated with COVID-19 Cases in a Large Urban Sewershed. Environmental science \& technology 2020.

10. Ahmed, W.; Angel, N.; Edson, J.; Bibby, K.; Bivins, A.; O'Brien, J. W.; Choi, P. M.; Kitajima, M.; Simpson, S. L.; Li, J., First confirmed detection of SARS-CoV-2 in untreated wastewater in Australia: a proof of concept for the wastewater surveillance of COVID-19 in the community. Science of the Total Environment 2020, 728, 138764.

11. Bivins, A.; North, D.; Ahmad, A.; Ahmed, W.; Alm, E.; Been, F.; Bhattacharya, P.; Bijlsma, L.; Boehm, A. B.; Brown, J., Wastewater-based epidemiology: global collaborative to maximize contributions in the fight against COVID-19. ACS Publications: 2020. 
12. Gonzalez, R.; Curtis, K.; Bivins, A.; Bibby, K.; Weir, M. H.; Yetka, K.; Thompson, H.; Keeling, D.; Mitchell, J.; Gonzalez, D., COVID-19 surveillance in Southeastern Virginia using wastewater-based epidemiology. Water research 2020, 186, 116296.

13. Sherchan, S. P.; Shahin, S.; Ward, L. M.; Tandukar, S.; Aw, T. G.; Schmitz, B.; Ahmed, W.; Kitajima, M., First detection of SARS-CoV-2 RNA in wastewater in North America: a study in Louisiana, USA. Science of The Total Environment 2020, 743, 140621.

14. Medema, G.; Been, F.; Heijnen, L.; Petterson, S., Implementation of environmental surveillance for SARS-CoV-2 virus to support public health decisions: Opportunities and challenges. Current Opinion in Environmental Science \& Health 2020.

15. Gerrity, D.; Papp, K.; Stoker, M.; Sims, A.; Frehner, W., Early-pandemic wastewater surveillance of SARS-CoV-2 in Southern Nevada: Methodology, occurrence, and incidence/prevalence considerations. Water research $X 2021,10,100086$.

16. Symonds, E.; Verbyla, M.; Lukasik, J.; Kafle, R.; Breitbart, M.; Mihelcic, J., A case study of enteric virus removal and insights into the associated risk of water reuse for two wastewater treatment pond systems in Bolivia. Water research 2014, 65, 257-270.

17. Haramoto, E.; Kitajima, M.; Hata, A.; Torrey, J. R.; Masago, Y.; Sano, D.; Katayama, H., A review on recent progress in the detection methods and prevalence of human enteric viruses in water. Water research 2018, 135, 168-186.

18. Corpuz, M. V. A.; Buonerba, A.; Vigliotta, G.; Zarra, T.; Ballesteros Jr, F.; Campiglia, P.; Belgiorno, V.; Korshin, G.; Naddeo, V., Viruses in wastewater: occurrence, abundance and detection methods. Science of the Total Environment 2020, 745, 140910.

19. Olson, M. R.; Axler, R. P.; Hicks, R. E., Effects of freezing and storage temperature on MS2 viability. Journal of virological methods 2004, 122 (2), 147-152.

20. Rzeżutka, A.; Cook, N., Survival of human enteric viruses in the environment and food. FEMS microbiology reviews 2004, 28 (4), 441-453.

21. Bertrand, I.; Schijven, J.; Sánchez, G.; Wyn-Jones, P.; Ottoson, J.; Morin, T.; Muscillo, M.; Verani, M.; Nasser, A.; de Roda Husman, A., The impact of temperature on the inactivation of enteric viruses in food and water: a review. Journal of Applied Microbiology 2012, 112 (6), 1059-1074.

22. John, D. E.; Rose, J. B., Review of factors affecting microbial survival in groundwater. Environmental Science \& Technology 2005, 39 (19), 7345-7356.

23. Gundy, P. M.; Gerba, C. P.; Pepper, I. L., Survival of Coronaviruses in Water and Wastewater. Food Environ. Virol. 2009, 1 (1), 10-14. 
24. Perreault, D. M.; Anslyn, E. V., Unifying the current data on the mechanism of cleavagetransesterification of RNA. Angewandte Chemie International Edition in English 1997, 36 (5), 432-450.

25. Soukup, G. A.; Breaker, R. R., Relationship between internucleotide linkage geometry and the stability of RNA. Rna 1999, 5 (10), 1308-1325.

26. Liu, M.; Gong, X.; Alluri, R. K.; Wu, J., Characterization of RNA damage under oxidative stress in Escherichia coli. Biological chemistry 2012, 393 (3), 123.

27. Li, Z.; Wu, J.; DeLeo, C. J., RNA damage and surveillance under oxidative stress. IUBMB life 2006, $58(10), 581-588$.

28. Ahmed, W.; Bertsch, P. M.; Bivins, A.; Bibby, K.; Farkas, K.; Gathercole, A.; Haramoto, E.; Gyawali, P.; Korajkic, A.; McMinn, B. R., Comparison of virus concentration methods for the RT-qPCRbased recovery of murine hepatitis virus, a surrogate for SARS-CoV-2 from untreated wastewater. Science of The Total Environment 2020, 739, 139960.

29. LaTurner, Z. W.; Zong, D. M.; Kalvapalle, P.; Gamas, K. R.; Terwilliger, A.; Crosby, T.; Ali, P.; Avadhanula, V.; Santos, H. H.; Weesner, K., Evaluating recovery, cost, and throughput of different concentration methods for SARS-CoV-2 wastewater-based epidemiology. Water Research 2021, 117043.

30. Gerba, C. P.; Betancourt, W. Q.; Kitajima, M.; Rock, C. M., Reducing uncertainty in estimating virus reduction by advanced water treatment processes. Water research 2018, 133, 282-288.

31. Seyhan, A. A.; Burke, J. M., Mg2+-independent hairpin ribozyme catalysis in hydrated RNA films. Rna 2000, 6 (2), 189-198.

32. Ma, S.; Huang, Y.; van Huystee, R., Improved plant RNA stability in storage. Analytical biochemistry 2004, 1 (326), 122-124.

33. Hernandez, G. E.; Mondala, T. S.; Head, S. R., Assessing a novel room-temperature RNA storage medium for compatibility in microarray gene expression analysis. Biotechniques 2009, 47 (2), 667-670.

34. Kansagara, A. G.; McMahon, H. E.; Hogan, M. E., Dry-state, room-temperature storage of DNA and RNA. Nature Methods 2008, 5 (9), iv-v.

35. Fabre, A.-L.; Colotte, M.; Luis, A.; Tuffet, S.; Bonnet, J., An efficient method for long-term room temperature storage of RNA. European Journal of Human Genetics 2014, 22 (3), 379-385.

36. Xie, X.; Bahnemann, J.; Wang, S.; Yang, Y.; Hoffmann, M. R., "Nanofiltration" enabled by superabsorbent polymer beads for concentrating microorganisms in water samples. Scientific Reports 2016, 6, 20516. 
37. Badiger, M.; Kulkarni, M.; Mashelkar, R., Concentration of macromolecules from aqueous solutions: a new swellex process. Chemical engineering science 1992, 47 (1), 3-9.

38. Iritani, E.; Iwata, M.; Murase, T., Concentration of proteinaceous solutions with superabsorbent hydrogels. Separation science and technology 1993, 28 (10), 1819-1836.

39. Prazeres, D., Concentration of BSA using a superabsorbent polymer: process evaluation. Journal of biotechnology 1995, 39 (2), 157-164.

40. Pellaux, R.; Heile, J.-m.; Schenzle, A. J.; Held, M., Method for the concentration and purification of biological compounds. Google Patents: 2010.

41. Cussler, E.; Stokar, M.; Varberg, J., Gels as size selective extraction solvents. AlChE journal 1984, $30(4), 578-582$.

42. Vartak, H.; Rele, M.; Rao, M.; Deshpande, V., A method for concentrating dilute solutions of macromolecules. Analytical biochemistry 1983, 133 (1), 260-263.

43. Wei, C.; Huang, Y.; Liao, Q.; Fu, Q.; Xia, A.; Sun, Y., The kinetics of the polyacrylic superabsorbent polymers swelling in microalgae suspension to concentrate cells density. Bioresource technology 2018, 249, 713-719.

44. Martin del Campo, J. S.; Patino, R., Harvesting microalgae cultures with superabsorbent polymers: desulfurization of Chlamydomonas reinhardtii for hydrogen production. Biotechnology and bioengineering 2013, 110 (12), 3227-3234.

45. Chen, W.; Wang, T.; Dou, Z.; Xie, X., Self-Driven "Microfiltration" Enabled by Porous Superabsorbent Polymer (PSAP) Beads for Biofluid Specimen Processing and Storage. ACS materials letters 2020, 2 (11), 1545-1554.

46. Tarelli, E.; Mire-Sluis, A.; Tivnann, H. A.; Bolgiano, B.; Crane, D. T.; Gee, C.; Lemercinier, X.; Athayde, M. L.; Sutcliffe, N.; Corran, P. H., Recombinant human albumin as a stabilizer for biological materials and for the preparation of international reference reagents. Biologicals 1998, 26 (4), 331-346.

47. An, F.-F.; Zhang, X.-H., Strategies for preparing albumin-based nanoparticles for multifunctional bioimaging and drug delivery. Theranostics 2017, 7(15), 3667.

48. Okay, O.; Sariisik, S. B., Swelling behavior of poly (acrylamide-co-sodium acrylate) hydrogels in aqueous salt solutions: theory versus experiments. European Polymer Journal 2000, 36 (2), 393-399.

49. Dika, C.; Duval, J.; Ly-Chatain, H.; Merlin, C.; Gantzer, C., Impact of internal RNA on aggregation and electrokinetics of viruses: comparison between MS2 phage and corresponding virus-like particles. Applied and environmental microbiology 2011, 77(14), 4939-4948. 
50. Schaldach, C.; Bourcier, W. L.; Shaw, H. F.; Viani, B. E.; Wilson, W., The influence of ionic strength on the interaction of viruses with charged surfaces under environmental conditions. Journal of colloid and interface science 2006, 294 (1), 1-10.

51. Pecson, B. M.; Martin, L. V.; Kohn, T., Quantitative PCR for determining the infectivity of bacteriophage MS2 upon inactivation by heat, UV-B radiation, and singlet oxygen: advantages and limitations of an enzymatic treatment to reduce false-positive results. Applied and environmental microbiology 2009, 75 (17), 5544-5554.

52. Weng, S.; Dunkin, N.; Schwab, K. J.; McQuarrie, J.; Bell, K.; Jacangelo, J. G., Infectivity reduction efficacy of UV irradiation and peracetic acid-UV combined treatment on MS2 bacteriophage and murine norovirus in secondary wastewater effluent. Journal of environmental management 2018, 221, 1-9.

53. Amsden, B., Solute diffusion within hydrogels. Mechanisms and models. Macromolecules 1998, 31 (23), 8382-8395.

54. Rattanakul, S.; Oguma, K., Analysis of hydroxyl radicals and inactivation mechanisms of bacteriophage MS2 in response to a simultaneous application of UV and chlorine. Environmental science \& technology 2017, 51 (1), 455-462.

55. Kluge, J. A.; Li, A. B.; Kahn, B. T.; Michaud, D. S.; Omenetto, F. G.; Kaplan, D. L., Silk-based blood stabilization for diagnostics. Proceedings of the National Academy of Sciences 2016, 113 (21), 58925897.

56. Mahfouz, N.; Caucci, S.; Achatz, E.; Semmler, T.; Guenther, S.; Berendonk, T. U.; Schroeder, M., High genomic diversity of multi-drug resistant wastewater Escherichia coli. Scientific reports 2018, 8 (1), 1-12.

\section{Figures}



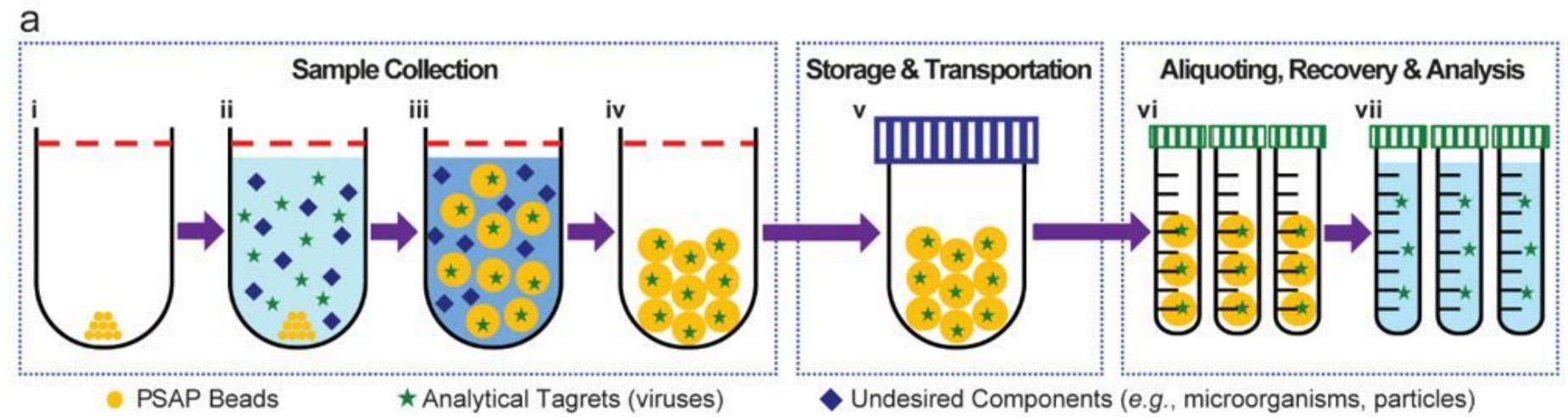

b
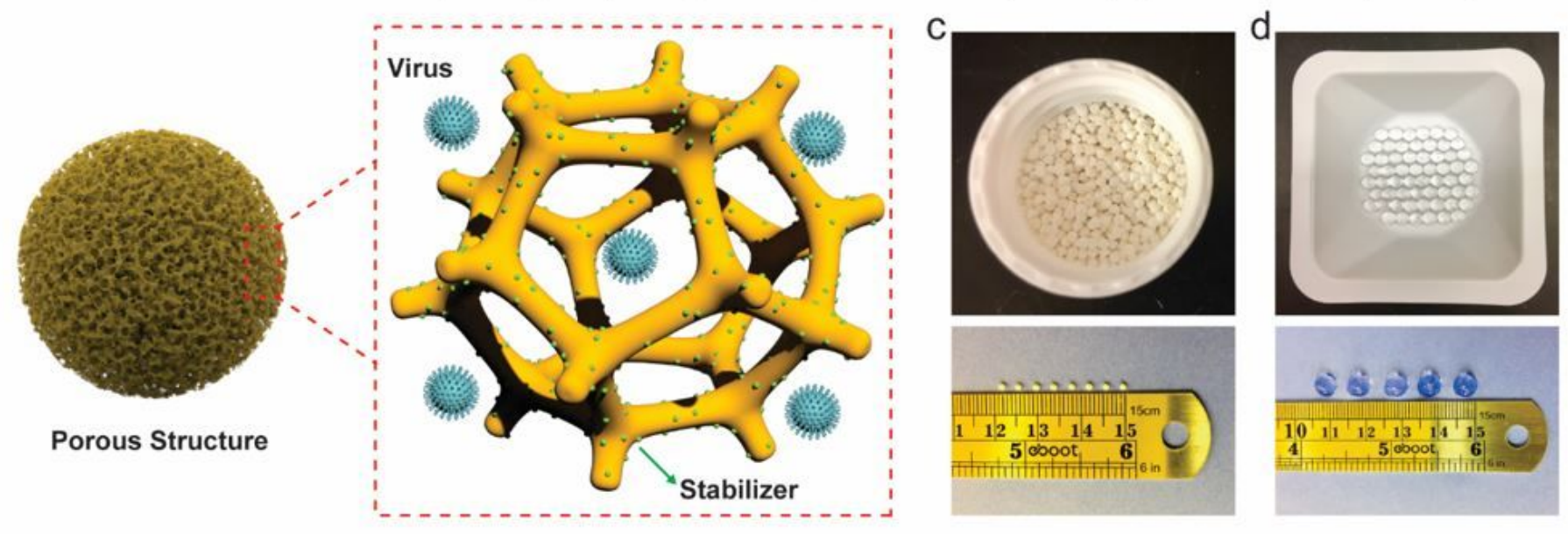

Figure 1

Enhanced PSAP beads for pretreatment and storage of viral targets in water samples. (a) Schematic of the treatment and recovery processes of viral targets using the PSAP beads. (b) Schematic of the PSAP beads. (c) Optical images of dried PSAP beads. (d) Optical images of hydrated PSAP beads. 
a
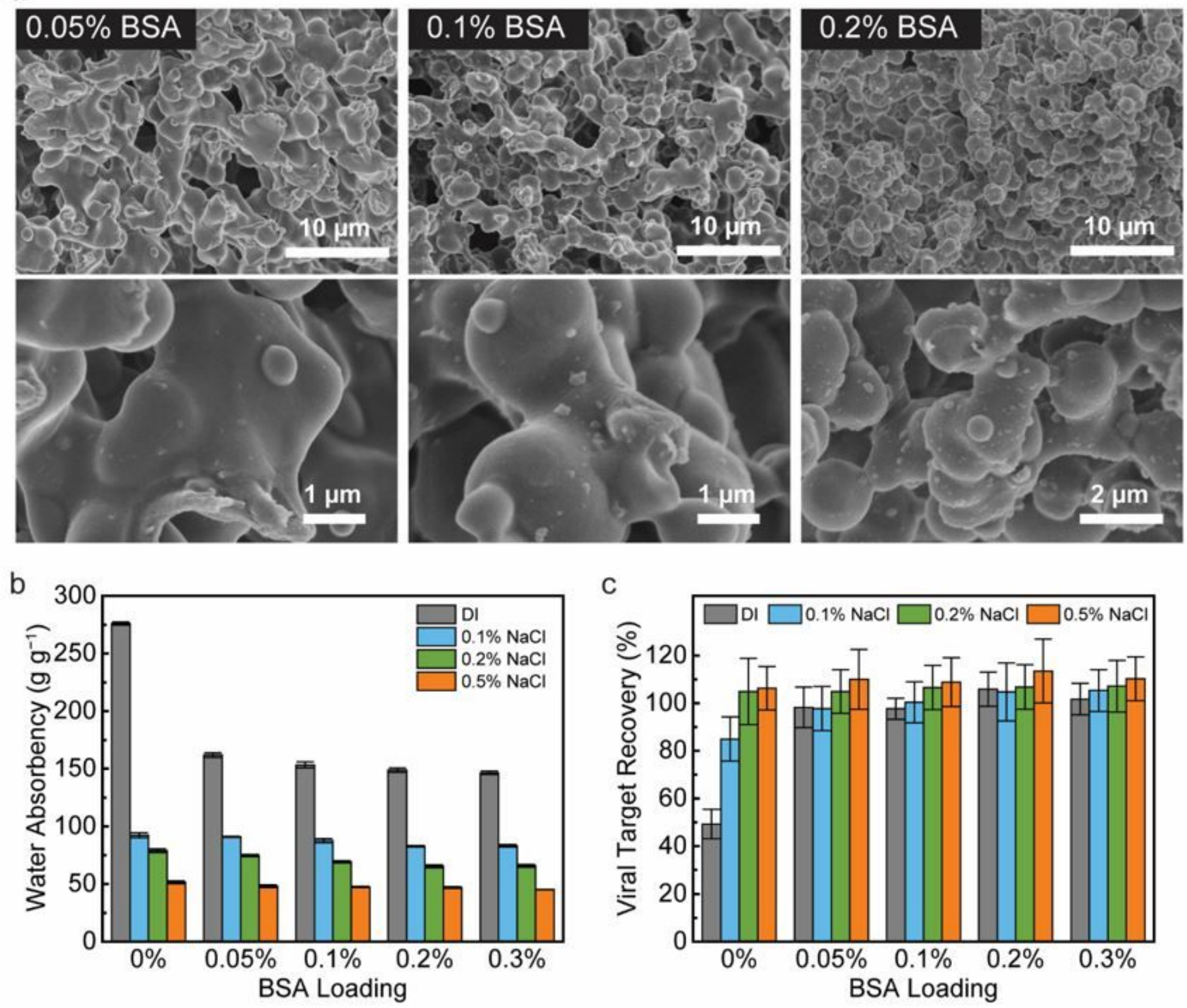

Figure 2

PSAP beads for virus absorption and recovery. (a) SEM images of the beads with different BSA loadings. The zoom-in SEM images show detailed features of the BSA distributed on the inner surface of those beads. (b) Water absorbency of the beads in DI water or saline solutions. (c) Recovery efficiency for bacteriophage MS2 in different media using the beads. 
a
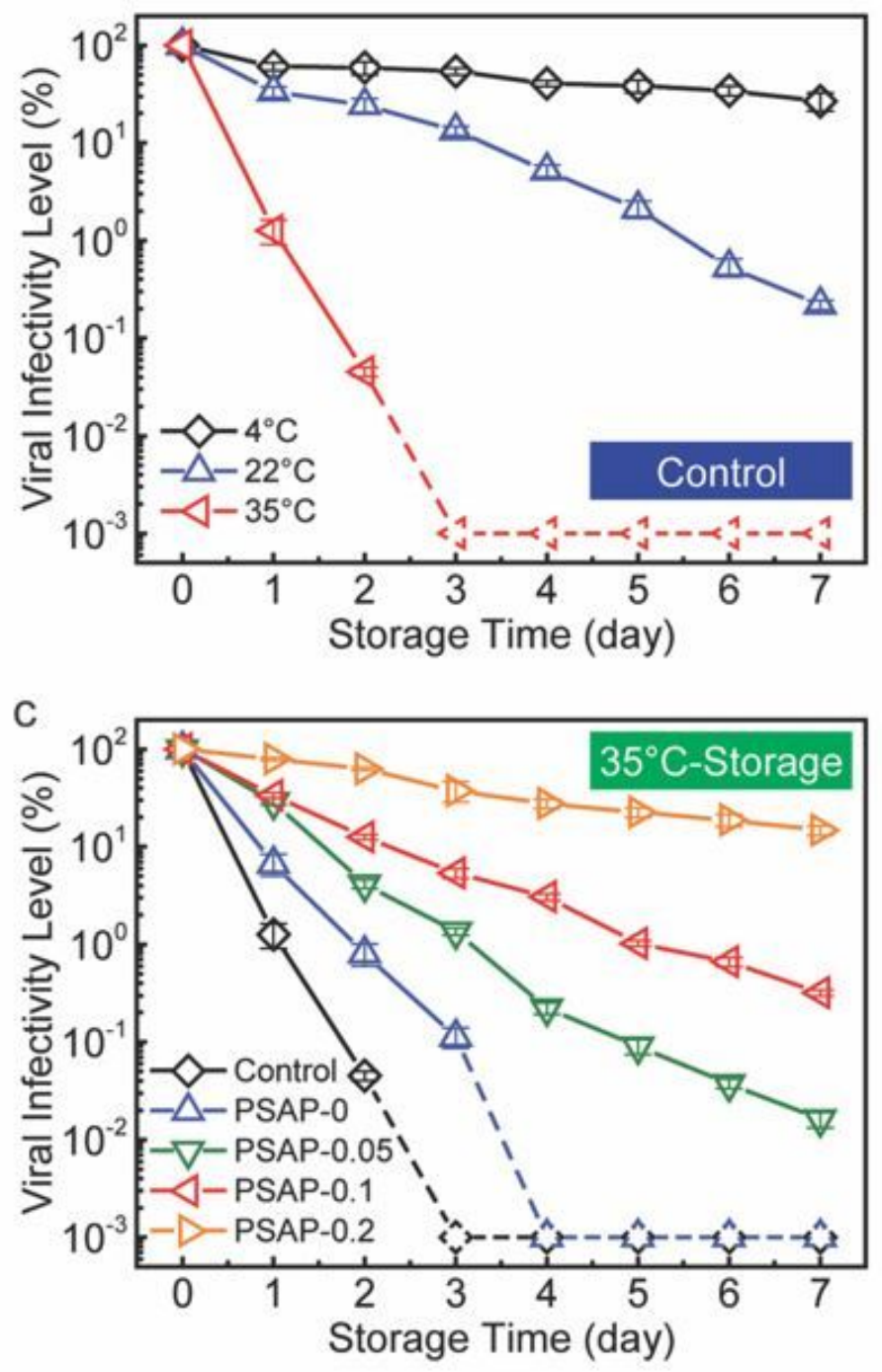

b
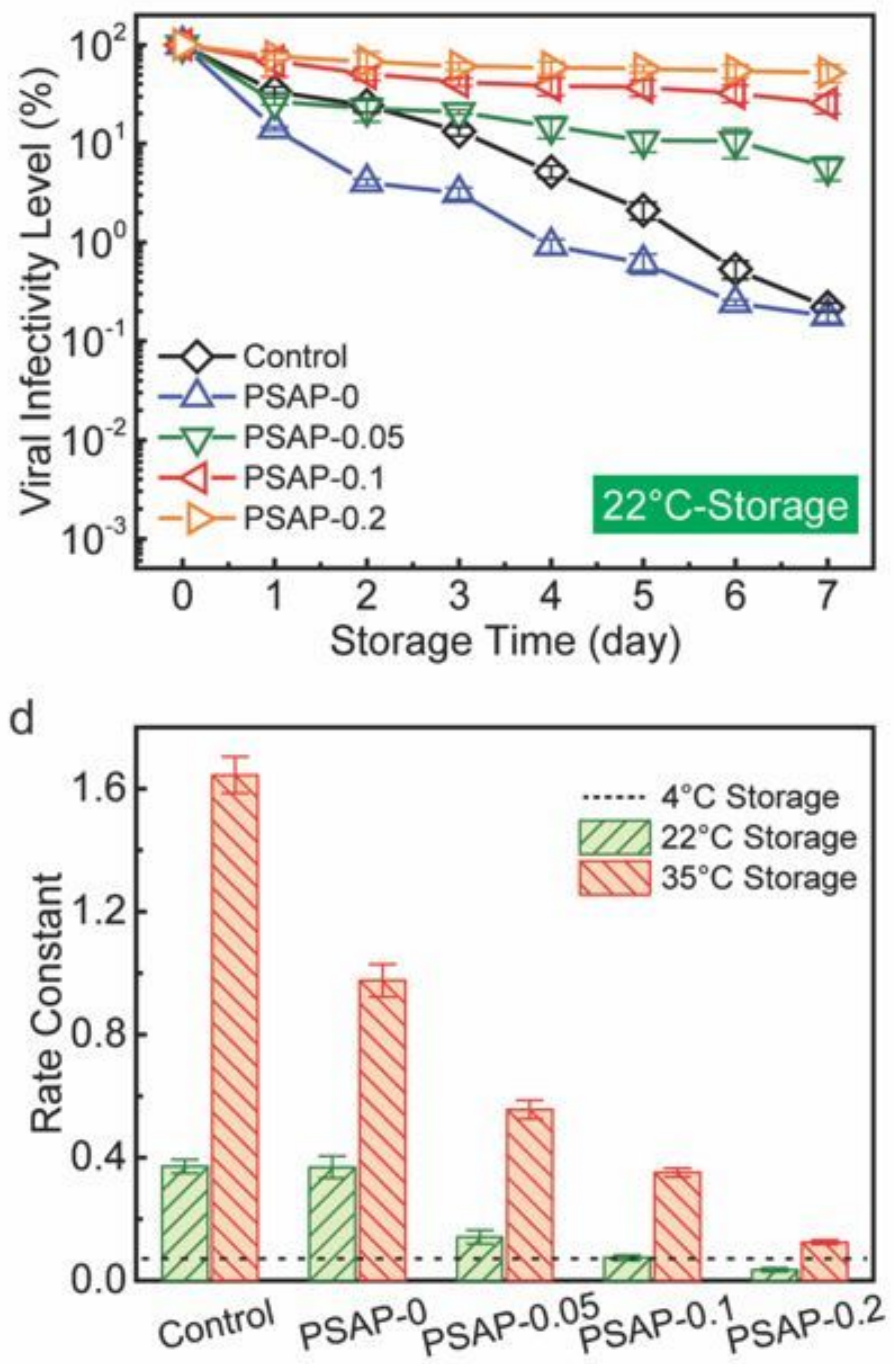

Figure 3

Shelf-life extension of bacteriophage MS2 using the PSAP beads. (a) Normalized viral infectivity in liquid control samples. (b-c) Normalized viral infectivity in hydrated PSAP beads at different temperatures. The legend "PSAP-0" means the PSAP beads with 0\% BSA, which applies to similar legends. The dashed lines in (a-c) indicate that no live virus is detected in agar plates. (d) Rate constants for viral infectivity reduction ( $k, \log 10$ PFU $m L-1$ day-1) during the 7-day storage. The black dotted line in (d) indicates the rate constant of the liquid sample stored at $4^{\circ} \mathrm{C}(\mathrm{k}=0.071 \pm 0.007 \log 10 \mathrm{PFU} \mathrm{mL}-1$ day -1$)$. 

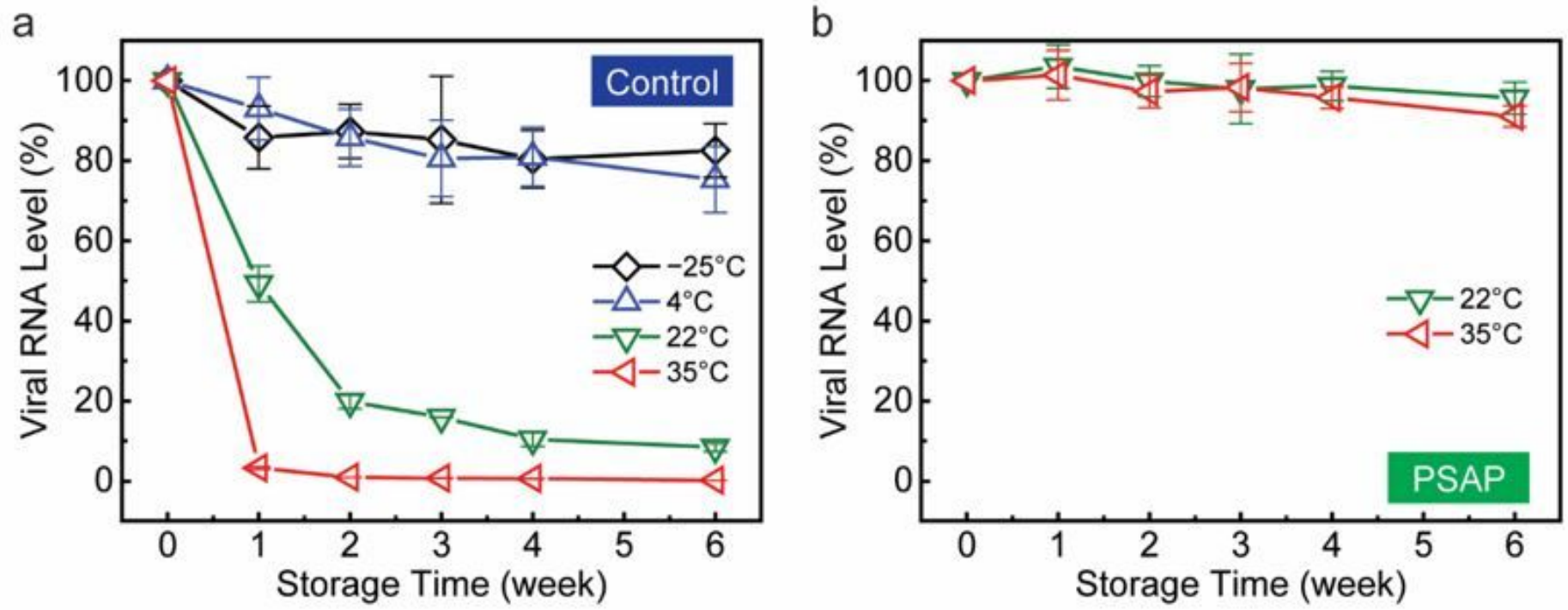

\section{Figure 4}

Viral genome stabilization performance during the long-term storage. (a) Residual viral RNA level in liquid control samples. (b) Residual viral RNA level in hydrated PSAP beads. The PSAP beads used were modified with $0.2 \%$ BSA. All storage experiments were conducted in a dark environment.
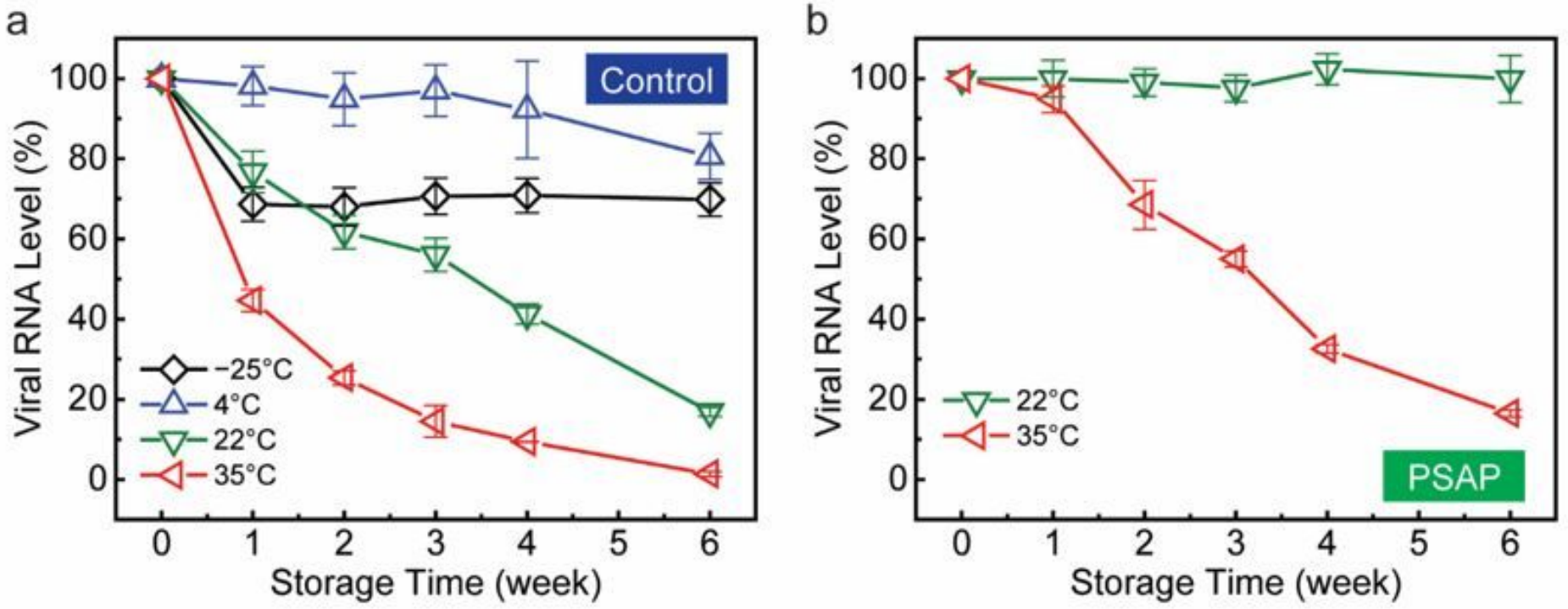

\section{Figure 5}

Virus preservation performance in untreated wastewater. (a) Residual viral RNA level in liquid control samples. (b) Residual viral RNA level in hydrated PSAP beads. The PSAP beads used were modified with $0.2 \%$ BSA. All storage experiments were conducted in a dark environment.

\section{Supplementary Files}


This is a list of supplementary files associated with this preprint. Click to download.

- SupportingEST.pdf 